\title{
Novas morfologias de trabalho: proteção legal e desafios pós-contemporâneos
}

\author{
New work morphology: legal protection and post-contemporary challenges
}

\author{
Saulo Nunes de Carvalho Almeida* \\ Maria Lírida Calou de Araújo e Mendonça**
}

\section{Resumo}

O presente artigo tem por escopo investigar a atual crise experimentada pelo direito do trabalho contemporâneo. Um direito que teve seu design normativo construído para regulamentar relações de trabalho em um sistema de organização empresarial do início do século XX, e que se encontra em xeque em virtude da proliferação de novas morfologias de trabalho que ocorrem a sua margem. Justifica esse breve ensaio a escassez de estudos direcionados ao enfrentamento da desproteção normativa experimentada por tantos trabalhadores. Restou evidenciado um cenário em que a capacidade do juslaboralismo contemporâneo de atuar com instrumento de compensação jurídica das desigualdades fáticas, bem como de assegurar o equilíbrio entre interesses econômicos e justiça social, tornou-se um privilégio experimentado tão somente por alguns poucos tipos de trabalhadores. Nesse contexto, o presente estudo emprega uma metodologia de análise jurídico-dogmática como ferramenta de desenvolvimento de seu objetivo central: questionar as possíveis transmutações pelas quais o direito do trabalho positivo deverá se sujeitar. Como conclusão, apresentou-se a imperativa necessidade de uma reformulação expansionista do direito laboral brasileiro, assegurando uma universalização dos direitos trabalhistas, a ser realizada mediante a identificação e compreensão da aplicabilidade de cada direito conforme as singularidades presentes em cada atividade laboral.

Palavras-chave: Novas formas de trabalho. Regulação trabalhista. Crise do direito do trabalho.

\section{Abstract}

The present article aims to investigate the current crisis experienced by contemporary labor law. A law that had its normative design built to regulate labor relations in a system of business organization of the early twentieth century, and which is in check by virtue of the proliferation of new work morphologies that occur at its margin. This short essay justifies the scarcity of studies aimed at coping with the normative lack of protection experienced by so many workers. It shows a scenario in which the capacity of the contemporary labor law to act with an instrument of legal compensation of the factual inequalities, as well as to ensure the balance between economic interests and social justice, became a privilege tried only by few type of workers. In this context, the present study employs a methodology of juridical-dogmatic analysis as a tool to develop its central objective, to question the possible transmutations for which labor law should be subject. As a conclusion, the imperative necessity of an expansionary reformulation of Brazilian labor law was presented, ensuring a universalization of labor rights, to be carried out by identifying the applicability of each right according to the singularities present in each labor activity.

Keywords: New ways of working. Labor regulation. Crisis of labor law.

Doutor e Mestre em Direito Constitucional nas Relações Privadas pela Universidade de Fortaleza - UNIFOR. Pós-Doutorando em Direito na Universidade de Fortaleza. Professor Universitário da UNICATÓLICA/Quixadá e UNIFANOR/Wyden. Fortaleza-CE-Brasil. E-mail: saulonunes@ hotmail.com.

- Doutora em Direito Público pela Universidade Federal de Pernambuco (UFPE). Mestre em Ordem Jurídica Constitucional pela Universidade Federal do Ceará (UFC). Professora titular do Programa de Pós-graduação em Direito Constitucional - Mestrado e Doutorado - e professora do curso de graduação em Direito da Universidade de Fortaleza (UNIFOR). Coordenadora e professora titular do curso de graduação em Direito do Centro Universitário Católica de Quixadá (UNICATÓLICA). Fortaleza-CE-Brasil. E-mail: liridacalou@unifor.br. 


\section{Introdução}

Com a globalização e a grande evolução tecnológica experimentada durante a última década, vivemos um novo mundo do trabalho, marcado por uma morfologia social diferenciada, com a integração do público e do privado, subordinações tênues, metamorfoses de classes e, em especial, novas modalidades de trabalho que surgem em nossa realidade, desprotegida das leis trabalhistas existentes.

Ao analisar essa sociedade emergente do trabalho, multifacetada e disforme, em especial no concernente aos direitos e garantias trabalhistas, Rodrigo de Lacerda Carelli (2004, p.17) aponta, entre as novas formas de prestação de serviços,

o trabalho temporário, o estágio, trabalho em tempo parcial, autônomos, falsos autônomos, cooperados, trabalhadores organizados em forma empresarial, eventuais, avulsos, 'free-lancers', domésticos, diaristas, horistas, empreiteiros, subempreiteiros, trabalhadores em tempo parcial, trabalhadores com emprego partilhado (job sharing), trabalhadores à distância [...], trabalhadores engajados por contratos civis. ${ }^{1}$

O quadro social, bem como o sustentáculo legal e jurisprudencial, dominante na sociedade contemporânea, leva-nos a uma dedução inevitável: o direito do trabalho brasileiro vive um momento de crescente instabilidade estrutural, oriunda de uma perda do controle social no que se refere à função de regular as novas relações de trabalho.

Nesse contexto, identifica-se uma disparidade da realidade social laboral com a capacidade do direito do trabalho adequadamente tutelar tais relações. Um cenário que, por óbvio, desperta preocupações, tendo em vista que "os princípios constitucionais encarnam juridicamente os ideais de justiça de uma comunidade, [...] através deles que se dará uma espécie de positivação constitucional dos valores do antigo direito natural" (SARMENTO, 2006, p. 79). Isso significa que o mundo jurídico tem como fonte o mundo social e ambos integram um mesmo caminho, inseparáveis. Um é o espírito, o outro é o corpo. ${ }^{2}$

Quanto à inquebrantável correlação entre justiça social e conduta humana, observa-se um princípio fortemente conexo aos padrões éticos e morais abraçados por uma sociedade, permitindo-se reconhecer, em maior ou menor grau, o direito de todos a viver com dignidade. Essa conduta humana merece ser vista como um sistema aberto, com características dinâmicas, suscetível a mutações conforme os valores que emergem ou se extinguem em cada época.

Não há como se contemplar o objetivo de justiça social sem perquirirmos, também, sobre o elemento "trabalho digno", verdadeira máxima do direito e indispensável para sua consecução. Partindo dessa conjugação, sabe-se que as relações trabalhistas são marcadas pela desigualdade de forças entre os contratantes, e "no capitalismo inúmeras relações econômicas são geradas de forma que uma das partes fique exposta à prepotência econômica da outra. Logo, prescindindo-se de uma intervenção protetiva do Estado" (NUNES JUNIOR, 2009, p. 115).

O grande abismo existente nas relações de trabalho, que separa os trabalhadores (economicamente desprovidos) dos empregadores, jamais será superado sem uma adequada intervenção protetiva do Estado. E aqui se manifesta a justiça social, atuando como um instrumento de compensação jurídica das desigualdades fáticas, destinado à busca pelo equilíbrio entre interesses econômicos e os direitos fundamentais do trabalhador, assegurando, aos menos favorecidos, a garantia de uma equalização de oportunidades.

O presente estudo jurídico tem como objetivo nuclear questionar o atual descompasso identificado entre as relações sociolaborais e o Direito positivo do trabalho, campo responsável em reger adequadamente

É oportuno destacar que, no contexto brasileiro, a gênese do pós-fordismo remonta aos momentos finais da década de 1980, conforme explica Ruy Braga (2014, p. 27): "A vitória de Fernando Collor, em 1989, representou a transição para regulação neoliberal: a partir de então, o próprio regime de acumulação transformou-se em objeto de sucessivos ajustes estruturais que acabaram por assegurar o nascimento do pós-fordismo financeirizado no país. Apesar do aperfeiçoamento do modo de regulação promovido pela burocracia lulista, esse regime de acumulação consolidouse em grandes contratempos ao longo dos anos 2000."

Evita-se, dessa forma, a máxima de Georges Ripert, que alertava que: "Quando o direito ignora a realidade, a realidade se vinga, ignorando o direito". 
as manifestações (juridicamente válidas) de aquisição da força de trabalho humana. Justifica a escolha temática o fato de que, apesar de sua relevância para os contratos de trabalho moderno, a questão ainda não se tornou alvo prioritário da literatura jurídica, sendo temática pouco investigada entre os especialistas do campo do juslaboralismo. Por fim, será adotada uma metodologia pautada em análises jurídico-dogmática, empregando um procedimento descritivo e exploratório, composto, essencialmente, pela análise de fontes de pesquisas bibliográficas.

Para conferir ao leitor melhor compreensão da lógica do método construtivo seguido pelo presente artigo, faz-se adequado apresentar uma breve exposição sistemática de como a matéria será abordada. A divisão adotada tem como capítulo introdutório identificar a problemática oriunda do desenvolvimento e difusão de novas morfologias de trabalho, prestadas sem a adequada tutela do direito laboral. No capítulo segundo, alguns aspectos históricos e conceituais da inserção dos ideários liberalistas no direito do trabalho serão investigados e criticamente questionados. Por fim, no capítulo conclusivo, adentra-se o que pode ser compreendido como hipótese do presente estudo, sendo perquirida a necessidade de trilhar um caminho de expansão normativa e novos arranjos jurídicos pelo direito do trabalho.

\section{Novas morfologias laborais e a crise do direito do trabalho contemporâneo}

A relação de emprego direta, espécie laboral dominante durante o século $X X$, vem experimentando um processo gradual de redução no curso do século XXI, sendo substituída por novas morfologias laborais, que surgem e dão ao empresariado alternativas para evitar os elevados encargos sociais incidentes sobre contratações de "empregados tradicionais". Isso significa que o tão debatido fenômeno da precarização social alterou sua clássica forma, possuindo agora uma nova feição, um novo problema. Se fizermos uma breve reflexão histórica, atentaremos a que, até o século XIX, a ameaça repousava nas sociedades escravocratas. Durante a parte introdutória do século XX, essa agressão assentava-se no trabalho fabril desgastante e no desemprego. Já no decorrer da década de 80 e 90, repousava na informalidade. Atualmente, a ameaça encontra-se presente na exploração das múltiplas novas formas de trabalho que, normatizadas ou toleradas pelo Estado, contribuem para a degradação do homem nos mais distintos campos de atividade econômica. ${ }^{3}$

Vivencia-se, no Brasil contemporâneo, uma nova tendência global, um fenômeno que o sociólogo Claus Offe (1995) refere-se como "capitalismo desorganizado", um processo de enfraquecimento da classe operária por meio da busca da bancada empresarial pela máxima flexibilização das normas e regulações trabalhistas. Altera-se o mundo do trabalho, amoldando-o às necessidades do capital globalizado. Um processo de redução de geração de empregos, acompanhada de um aumento na geração de trabalhos.

Essa situação caótica é interpretada por muitos especialistas como uma tendência mundial resultante da nova era que adentramos, chamada de "Era Informacional", e com a qual surge um novo paradigma, o da economia informacional. Trata-se de um quadro de plena fruição do capital globalizado, caracterizado pela superação das barreiras territoriais e pela internacionalização do comércio, fazendo surgir um nível de concorrência global a ser enfrentado por empresas locais.

Nesse processo de completa reestruturação produtiva, é essencial reconhecer que nem toda forma de labor humano deve ser considerada como bem-vinda, mesmo que rotulada como "solução ao desemprego", "resultado natural da globalização" ou "simples face da era informacional". Apesar de o trabalho ser uma necessidade do homem, certamente não é a única. Um trabalho que oprime, que degrada, que destrói e explora, traz maiores malefícios (sociais) do que benefícios (econômicos) e deve sempre ser confrontado

Na lição de Eliana Calmon (2001, p. 45), o Estado tem experimentado grandes dificuldades em barrar a regressão dos direitos sociais que, invariavelmente, acarreta em certo grau de esvaziamento dos direitos e garantias fundamentais. A título de exemplo, a autora destaca que, no Brasil: "aumenta o número de contratos a termo, subcontratos, [...] e surgem novas formas de remuneração com base na produtividade, exercidas as tarefas por microempresários, deixando-se livre a negociação, sem a preocupação de proteger o hiposuficiente". 
pelo Estado. ${ }^{4}$ Isso faz com que a regulação adequada do trabalho corresponda a um dos grandes desafios da atualidade, tendo em vista a complexa busca pelo ponto de equilíbrio entre os ideais globais do capitalismo e a busca pela efetivação de valores humanos indisponíveis.

A Consolidação das Leis do Trabalho, grande responsável pela proteção social dos trabalhadores no Brasil, ${ }^{5}$ experimenta dificuldades para alcançar a plenitude de seu objetivo original. Os dez membros da comissão que, no ano de 1942, elaboraram o anteprojeto dessa norma que, em 1943, passou a vigorar em todo o país, jamais poderiam prever os avanços nas relações sociais, econômicas e tecnológicas ${ }^{6}$ experimentadas pela nação brasileira nas ultimas décadas. Seu objetivo essencialmente era, naquele momento dos primórdios da formação de uma sociedade industrial, reger as relações jurídicas entre o empregador e o operário no espaço fabril, ${ }^{7}$ como relembra Luiz Marcelo de Gois (2010, p. 31):

O paradigma utilizado pelo Direito do Trabalho para a construção de suas normas e princípios, como não poderia deixar de ser, foi o modelo empresarial existente àquela época. A relação de trabalho, foco da tutela do ordenamento, era aquela travada dentro da indústria - principalmente na grande indústria - onde a linha de montagem havia sido implementada, elevando-se tal paradigma de trabalho a um status de modelo 'típico' para o Direito do Trabalho.

Com o advento da "Era da Tecnologia", a CLT tem encontrado dificuldades em acompanhar os rumos que foram seguidos pela estrutura produtiva do país, marcado pelo dinamismo ${ }^{8}$ e pela criação de novas formas de trabalho, em especial pela descaracterização dos clássicos requisitos utilizados para o reconhecimento da relação de emprego.

Entre as novas morfologias que contribuem na deterioração dos direitos sociais, e que põe em xeque o sistema jurídico laboral, destacam-se a proliferação do trabalho temporário, o contrato de experiência, o trabalho autônomo, o terceirizado, o cooperado, o pseudo associado, o representante comercial, o empreiteiro, o subempreiteiro, o "chapa", o freelancer, entre outras heterogeneidades que, frente à inaplicabilidade da CLT,

Ana Virgínia Moreira Gomes (2001, p. 101-102) nos relembra que: "Desde a própria origem do Direito do Trabalho, nota-se o caráter social de suas normas: é interesse de toda a sociedade, é um direito da sociedade não conviver com situações de trabalho indignas de um homem. [...]. Os direitos sociais limitam a autonomia dos indivíduos, porém não de forma paternalista, tomando decisões adstritas apenas à esfera privada de cada um, mas, sim, no interesse da própria sociedade".

5 Quando a instituição da CLT, no ano de 1943, a Constituição que encontrava-se em vigor era a de 1937, notoriamente desrespeitada pela estigmatização de que na Constituição não caberia obrigações direcionadas aos particulares, esses acreditavam no ideário de que deveriam ser regidos pela legislação privatistica (Código Civil), e não pública. Para o professor Grijalbo Fernandes Coutinho (2009, p. 37), isso significa que, apesar de estabelecer grandes retrocessos ao direito coletivo do trabalho, não se deve negligenciar o fato de que a CLT "ampliou, nas perspectivas de alcance e de quantidade, os direitos trabalhistas, tais como as férias anuais remuneradas, a jornada semanal, o salário mínimo, o descanso semanal e a contratação do trabalhador por prazo indeterminado como regra, dentre outras garantias. O discurso que relaciona o surgimento do Direito do Trabalho no Brasil e da própria CLT a uma inspiração fascista de Vargas tem o claro propósito de desqualificar a luta incessante de mais de três décadas da classe trabalhadora brasileira e, por conseguinte, está revestido de forte conteúdo ideológico contra a mais expressiva conquista social da cidadania alcançada por uma nação." Hodiernamente, a Constituição Federal alcançou novo patamar de reconhecimento e valorização, e agora atua em conjunto com a CLT como maiores responsáveis pela normatização protetora dos direitos sociais do trabalhador no Ordenamento brasileiro.

6 Conforme esclarece Jacquelina Imbrizi (2005, p. 95): “A denominação 'inovações tecnológicas' está relacionada à especificidade do progresso técnico que a partir da década de 1970 demarcou mudanças na sociedade. Do ponto de vista do mundo do trabalho, elas referem-se à adoção das inovações tecnológicas de base física que desencadearam o surgimento de novas técnicas organizacionais em contraposição à organização do trabalho taylorista-fordista." Esse paradigma de organização dominaria o trabalho humano até os anos 80 , momento que colidiria frente a necessidade empresarial de construção de cadeias mais complexas. Assim, passaria a exibir "seus primeiros sinais de exaustão com a crise da IBM norte-americana, em meados dos anos 80. A partir de então, a organização dos processos produtivos passou a seguir um itinerário marcado pela fragmentação e pela dispersão, em unidades produtivas autônomas, dotadas de crescente vocação para a especialidade e para a otimização dos resultados gerenciais num cenário de competitividade internacional" (FREITAS JR., 2011, p. 22).

Apresentando o modelo clássico de empregador à luz da tutela jurídica do Direito Laboral brasileiro, Luiz Marcelo Figueiras de Góis (2010, p. 32) ressalta que: "O empregador típico para o Direito do Trabalho é a empresa baseada, em regra, na linha de montagem e nas técnicas fordistas e tayloristas de produção, com forte hierarquização e divisão de tarefas." Todavia, Dinaura Godinho Pimentel Gomes (2007, p. 20) nos lembra que "Os postos de trabalho antes ocupados por operários, nas fábricas, vem sendo substituídos, com mais frequência, pela força de trabalho intelectual, a exigir a adoção de novos métodos de produção introduzidos pela alta tecnologia".

8 Jaquelina Maria Imbrizi (2005, p. 117), ao analisar a experiência do trabalho na sociedade contemporânea, aponta que: "No mundo do trabalho a exigência de mudanças constantes transformou as formas de organização da produção e do processo de trabalho. Do tempo linear e rigidamente controlado das linhas de montagem passa-se para o tempo descontínuo, flexível e autônomo. O que vai indicar mudanças nas habilidades requeridas para o trabalho, entre elas, a intensa atividade mental". Complementando, Jorge Luiz Souto Maior (2000, p. 245) leciona que "A evolução das relações sociais exige novas respostas do direito a cada momento. Exige, portanto, uma atividade atenta de legisladores, doutrinadores, juízes e dos vários centros de positivação do direito, no sentido de comporem um direito aplicável a seu tempo. Assim, o direito é uma construção consciente do homem, que está sempre em movimento, acompanhando a evolução social, exatamente para não morrer, e é, por isso mesmo, um sistema carregado de contraditoriedades, tendo a noção de princípios, precisamente, a função de inibir a ação destruidora dessa contradição." 
possuem contornos semelhantes (ou idênticos) ao trabalho informal ${ }^{9}$. A consequência dessa desumanização laboral é que tudo é convertido em precariedade, substitui-se o direto pelo indireto, o certo pelo incerto, o trabalho formal pelo informal, o próspero pelo precário, o digno pelo indigno. ${ }^{10}$

\section{Como chegamos a esse estágio?}

\section{Primórdios da desestruturação do direito do trabalho e o retorno dos ideários contratualistas}

A nascente desse sistema de desestruturação dos ideais do "Estado assistencial" (Welfare State) pode facilmente ser rastreada. A presença dessas complexas novas relações de trabalho tornaram-se comuns em países como EUA e Grã-Bretanha que, influenciados pelos ideais do liberalismo econômico, nunca abraçaram totalmente a legitimidade dos princípios do Welfare State. Com o término da Guerra Fria, as regras de um mercado liberal passaram a desfrutar de um grande prestígio e, com o fenômeno da globalização, doutrinas ultraliberais difundiram-se, sendo importadas para os demais países do hemisfério, consolidando uma nova polissemia do trabalho, marcado por maiores graus de dominação de um agente hipersuficiente sobre outro hiposuficiente, mais precisamente do empregador sobre o trabalhador.

A combinação dessas novas formas de trabalho, e a sua plena adoção pelas empresas, contribuem ao tão debatido paradigma de precarização de direitos trabalhistas. Empresas adotantes de uma gestão baseada apenas em resultados passam a eliminar direitos sociais, pois representam gastos. Gastos esses que, ao final, afetam diretamente os lucros obtidos por uma entidade organizacional, o que faz com que, sob uma ótica estritamente econômica, correspondam a supressões racionalmente justificadas. ${ }^{11}$

Assim, prospera o atual sistema socioeconômico, de forma enxuta, sem custos considerados "desnecessários", interpretando direitos sociais como casualidades e as novas morfologias de trabalho como uma viável alternativa de barateamento de seus encargos, racionalizando economicamente todas as suas escolhas e decisões, eliminando o espaço para valores éticos, e reflexões acerca da função social da empresa ou os limites morais no mercado. ${ }^{12}$ Atribui-se valor financeiro a direitos fundamentais, resultando em uma perigosa alteração no eixo social, migrando de uma economia de mercado e adentrando uma verdadeira sociedade de mercado. ${ }^{13}$

Esse é o "império da economia", e aparentam serem essas as novas regras do jogo de um mercado global. Frente esse cenário contemporâneo:

Não se pode conceber que os trabalhadores que não sejam empregados tenha negada aplicabilidade aos seus direitos fundamentais trabalhistas. Ora, a complexidade social implica o polimorfismo do trabalho. Daí decorre, sob o paradigma democrático de direito, a premência de que o Direito do Trabalho se renove em suas diretrizes para não falhar em sua missão de proteger o trabalhador em suas múltiplas facetas. Isso porque o estandarte protetivo do ramo jurídico trabalhista não admite que a proteção para alguns conviva com a desproteção para outros tantos trabalhadores. Assim, o arcabouço constitucional do Direito do Trabalho impõe ao seu interprete o reconhecimento de que todos têm direitos. Deve-se, portanto, estar sempre alerta para concretizar sua vocação universalizante por

9 Conforme analisa Guy Standing (2014), a própria gênese do termo "precariado" está associado a espécies de contratos de trabalho de subempregabilidade, marcados pela falta de benefícios básicos aqueles trabalhadores, que não são assegurados seja pela empresa, seja pelo próprio Estado.

10 É relevante ressalvar que é possível pensar em situações em que a aplicação dessa nova morfologia laboral se manifesta por um ato de vontade autêntica do próprio trabalhador. Refiro-me às novas espécies de trabalhos intelectuais que começam a se fazer presentes frente à evolução comunicacional oriunda da Revolução Digital. São trabalhadores independentes, que não apenas se encontram fora do "status" de vulnerabilidade, mas também anseiam por uma maior autonomia e liberdade, tanto na forma de execução de seu trabalho, quanto nos momentos em que o trabalho será prestado e, por isso, entendem como vantajoso que a prestação de seus serviços ocorra fora dos moldes da tradicional "relação empregatícia”. Adequada a ressalva de que esses trabalhadores correspondem à exceção, não à regra, da força de trabalho no Brasil.

11 Aspecto comumente objeto de estudo pela chamada escola de Law and Economics ao investigar as repercussões sociais da chamada "Teoria dos incentivos".

12 Para melhor reflexão sobre o tema, aconselhamos análise das obras dos filósofos americanos Michael Sandel, "O que o Dinheiro não Compra: Os Limites Morais do Mercado" e Eduardo Porter, "O Preço de Todas as Coisas: Por que Pagamos o que Pagamos"..

13 Jaquelina Maria Imbrizi (2006, p. 59) argumenta que "é a estrutura da sociedade capitalista que oferece as condições para a formação de homens eminentemente práticos que já não conseguem exercitar o que os caracteriza humanos: a capacidade de reflexão". 
meio da inclusão, sob os contornos jurídicos adequados, das novas e renovadas formas de trabalho que emergirem. (FRANCESCHET, 2012, p. 323).

Nesse passo, tem-se defendido que a vitalidade do direito do trabalho exige que essa ciência transmute-se em um sistema aberto às transformações sociais e econômicas, permitindo uma evolução de suas fontes e instituições, reconhecendo algumas tendências do direito constitucional moderno como adequadas ao período atual; em especial, as teorias jurídicas ascendentes, como a eficácia horizontal e imediata dos direitos fundamentais, neoconstitucionalismo ${ }^{14} \mathrm{e}$ os direitos de cidadania do trabalhador. Para isso, as necessidades comerciais e de mercado não podem continuar a ser apresentado como motivo legítimo para defender o retrocesso das condições de trabalho arduamente conquistadas por uma sociedade.

A defesa da criação de normas protecionistas que incidam sobre as demais formas de relação de trabalho corresponde a um dever do Estado brasileiro, estabelecido pela Constituição Federal de 1988, por meio dos artigos $1^{\circ}$, incisos III e IV; $3^{\circ}$, inciso III e $6^{\circ}$, que garantem que a todo o trabalho deverá ser assegurado os direitos sociais, a dignidade humana ${ }^{15}$ e uma justa distribuição de renda. Diretrizes de um Estado democrático que têm sido ignoradas pelo legislador infraconstitucional ao falhar em estabelecer uma tutela normativa condizente com as novas demandas sociais, em especial as transformações experimentadas pelo trabalho com o surgimento das novas categorias de "trabalhadores não-empregados".

Nesse cenário de relações de trabalho heterogêneas e precarização estrutural, a legislação laboral necessita evoluir, abraçando essa multifacetada classe trabalhadora que domina o cenário organizacional brasileiro. Sua estagnação significa a fragmentação dos direitos sociais e a exclusão de milhões de cidadãos que, apesar de venderem sua força de trabalho, não alcançam os clássicos elementos da relação de emprego positivados pelos artigos $2^{\circ}$ e $3^{\circ}$ da CLT. Sampaio (1979, p. 50) já apontava que:

O direito do trabalho, a nosso ver, deve evoluir para um direito que vise proteger o trabalhador não apenas como fator de produção, mas como ser humano. Deve almejar integrá-lo na sociedade, e não apenas na empresa, porque aquele é duradoura e esta nem sempre o é. A pessoa deve ser protegida por sua humana condição e não apenas enquanto força de trabalho. Essa nova concepção do direito [...] é mais eficaz que a vigente, porque mais genérica e não restrita ao trabalhador vinculação a relação de trabalho subordinado. Porque deve o trabalhador subordinado ter melhor proteção do que o trabalhador autônomo - se este é tão importante para a sociedade quanto aquele? Um regime jurídico que seja aplicável a todos os que, de uma forma ou de outra, dão sua contribuição à sociedade, deve receber equivalente retribuição ou reconhecimento.

Por isso, melhor seria iniciarmos debates em torno da incorporação legal da totalidade da classe trabalhadora, refletindo como inserir as múltiplas relações de trabalho (não apenas a relação de emprego) no núcleo protetivo das normas estatais. Arnaldo Sussekind (2003, p. 21) alertava que:

[...] a globalização da economia acirrou a polêmica entre os defensores do Estado Social e os adeptos do Estado Liberal, os quais, obviamente, adotaram caminhos distintos a respeito da posição dos poderes públicos, frente às relações de trabalho. Os neoliberais pregam a omissão do Estado, desregulamentando, tanto quanto possível, o Direito do Trabalho, a fim de que as condições de emprego sejam ditadas basicamente pelas leis do mercado. Já os defensores do Estado Social, esteados na doutrina social da Igreja ou na filosofia trabalhista, advogam a intervenção estatal nas

\footnotetext{
4 Humberto Ávila (2009, p. 1), analisando a teorização do neoconstitucionalismo, entende que "não há apenas um conceito de neoconstitucionalismo. A diversidade de autores, concepções, elementos e perspectivas e tanta, que torna inviável esboçar uma teoria única do neoconstitucionalismo." Todavia, apesar dessa pluralidade teórica, demonstra-se adequada a reflexão desenvolvida por Luis Roberto Barroso e Ana Paula de Barcellos (2003, p. 60) acerca do tema: "O pós-positivismo é a designação provisória e genérica de um ideário difuso, no qual se incluem a definição das relações entre valores, princípios e regras, aspectos da chamada nova hermenêutica constitucional, e a teoria dos direitos fundamentais, edificada sobre o fundamento da dignidade humana. A valorização dos princípios, sua incorporação, explícita ou implícita, pelos textos constitucionais e o reconhecimento pela ordem jurídica de sua normatividade fazem parte desse ambiente de reaproximação entre Direito e Ética".

15 Segundo Marcos Juruena Villela Souto (2000, p. 169): "Toda estrutura do Estado, os três poderes em termos de repartição espacial do Poder, a União, o Estado e o Município, e em termos de repartição funcional do Poder, Legislativo, Executivo e Judiciário, essa estrutura estatal se molda para que os objetivos do Estado, ou seja, da busca da sociedade livre, justa, solidária, da erradicação da pobreza, da busca do pleno emprego e do desenvolvimento econômico, sejam alcançados". Todavia, Elival da Silva Ramos (2010, p.53) alerta que "a consecução dos objetivos fundamentais generosamente estipulados no art. $3^{\circ}$, da CF/1988 (construir uma sociedade livre, justa e solidária; garantir o desenvolvimento nacional; erradicar a pobreza e a marginalização; e reduzir as desigualdades sociais e regionais), instrumentalizada, em boa dose, pela efetivação dos direitos sociais de que trata a norma programática do art. $6^{\circ}$, caput, da CF/88, depende de uma ampla e coordenada atuação do Estado."
} 
relações de trabalho, na medida necessária à efetivação dos princípios formadores da Justiça social e à preservação da dignidade humana.

A legislação trabalhista, em sua atual forma, não se mostra à altura do desafio de combater essa organizada ofensiva ultraliberal, que prega, conforme afirmava Américo Plá Rodriguez, por um retorno no tempo a um período anterior ao Tratado de Versalhes. ${ }^{16}$ Considerando os contornos da reforma trabalhista ocorrida em 2017, aparenta ser seguro afirmar que o processo de flexibilização trabalhista ainda não encontrou nenhuma barreira capaz de contê-lo. Everaldo Gaspar Lopes de Andrade (2008, p. 83) esclarece que "foi a classe capitalista quem inventou o Estado Liberal e reivindicou para si a edição das leis, inclusive das leis trabalhistas, centradas no tal princípio protetor do contrato individual de trabalho. E todo conteúdo normativo veio para benefício dessa classe dominante, não o contrário."17

O autor complementa seu argumento, apontando que "primeiro vem o poder diretivo, por intermédio do qual se institui a exploração do trabalho vendido, comprado e apartado da vida e, depois, uma pseudoigualdade das partes. Vínculos ideológicos que se sustentam por meio do requisito essencial do contrato de trabalho: a subordinação."

Coadunando com o raciocínio, José Affonso Dallegrave Neto (2002, p. 21) exalta que "para melhor compreensão do atual movimento flexibilizador, faz-se mister registrar que as diretivas advieram de uma cartilha ditada pelos credores da dívida externa. A partir de então, verificou-se um fenômeno oposto aquele observado, quando do advento do Estado Social."

A cartilha ao qual se refere José Affonso Dallegrave Neto ficou conhecida pelo nome "Consenso de Washington". Para o Brasil, e muitos outros países em desenvolvimento, o Consenso de Washington, de 1989, pode ser visto como o "big bang" da desregulamentação trabalhista. Tratou-se de um conjunto de medidas formuladas pelo Fundo Monetário Internacional, o Banco Mundial e, por óbvio, o Departamento do Tesouro dos Estados Unidos que, aproveitando-se das dificuldades dos países emergentes, plantaram as sementes da desregulamentação em nações que desesperadamente necessitavam de recursos do FMI.

Entre as dez regras básicas do tratado, destacavam-se medidas como: redução dos gastos públicos (fortalecendo a atividade privada), privatização das estatais, abertura comercial (fortalecendo os conglomerados internacionais), direito à propriedade intelectual (protegendo as criações e inovações, comumente oriundas dos países ricos, em âmbito internacional) e, a mais relevante para o presente estudo, a desregulamentação das leis econômicas e trabalhistas, fortalecendo o livre mercado. ${ }^{18}$

Nesse cenário ideológico, críticas ao modelo de livre mercado não eram bem recebidas, sendo capazes, até mesmo, de acarretar no rótulo de "discursos socialistas" ou "anti-globalização", por isso não seriam merecedoras de maior reconhecimento.

Em uma perspectiva global, esse cenário começa a modificar com a crise do capital de 2008 (iniciada no berço do liberalismo, os EUA). Economistas e sociólogos começam a levantar vozes mais altas,

16 O Tratado de Versalhes foi o tratado de paz que, em 1919, oficialmente pôs um ponto final na Primeira Guerra Mundial. É reconhecido, também, como marco de consagração da autonomia científica do direito do trabalho, alargando significativamente seu objeto de proteção.

17 Para Arnaldo Sussekind (2003, p. 19), "quando se diz que a empresa está engessada por causa da CLT é uma inverdade, porque o Brasil é um dos países que mais flexibilizou a legislação do trabalho. Vou mostrar. Em 1974, utilização de trabalhadores de empresas de trabalho temporária - é uma flexibilização; em 1966, ampla liberdade patronal para despedir os empregados - Fundo de garantia por Tempo de Serviço; Constituição de 1988: quebra do princípio da irredutibilidade salarial por acordo ou convenção coletiva; ainda a Constituição, flexibilização da jornada de trabalho, facultadas a sua redução ou a compensação de horários por acordos ou convenção coletiva; ampliação da jornada e seis horas nos turnos ininterruptos de revezamento por meio de negociação coletiva; contrato de trabalho provisório com ampla redução de direitos; trabalho a tempo parcial (com o qual estou inteiramente de acordo, mesmo que seja uma flexibilização); terceirização de serviço em determinadas hipóteses, regulamentado pelo Enunciado n³31 deste Tribunal; redução das hipóteses de salário-utilidade pela Lei 243/01".

18 Ao analisar as diretrizes definidas pelo "Consenso de Washington", e suas influências nas teorias neoliberais, de internacionalização da economia e globalização dos mercados, Luiza Helena Moll (2000, p. 397), expõe que "implicaram abertura irrestrita dos mercados do $3^{\circ}$ mundo, a desregulamentação da economia, a privatização dos serviços públicos estratégicos por via da venda das empresas estatais para grupos de capitais privados, além de enquadrarem-se em uma moldura formatada pela aprovação da Lei de Patentes, o tratamento paritário do capital estrangeiro com o nacional, a Lei de Concessões e Permissões, medidas institucionais de caráter econômico, dentre outras políticas, tudo tendo como pano de fundo a renegociação da dívida externa e a dependência dos Estados Unidos em relação a seus devedores, num contexto em que se tornam cada vez mais dependentes de novos capitais, face à $3^{\circ}$ revolução industrial." 
clamando pela extinção das políticas e regras neoliberais que estruturavam o Consenso de Washington. Afinal, evidenciou-se que sistemas capitalistas que têm como princípio dominante a transformação da força de trabalho em mercadoria, produzem distúrbios ainda mais graves em Estados eminentemente liberais. Nesses sistemas, o mercado detém severa influência sobre a regulação das relações econômicas e laborais, acarretando a supressão de direitos e garantias individuais dos cidadãos-trabalhadores, em detrimento da criação de privilégios empresariais.

Agora, vivemos um período de transição. Conforme afirmou o economista Marcio Pochmann (2011, p. 127):

\begin{abstract}
A grande crise do capital globalizado, em 2008, indicou os limites das políticas neoliberais, bem como a regressão imposta ao mundo do trabalho pelo avanço da concentração econômica pelas grandes corporações transacionais. O movimento desencadeado pelas nações para a defesa da produção do emprego diante do agravamento da recessão internacional abre a nova perspectiva para a regulação das relações de trabalho.
\end{abstract}

Isso significa que começa a se a consolidar a doutrina que reconhece que a política ultraliberal econômica, oriunda do crescimento de ideários capitalistas sobre a organização de trabalho, acarretou graves distúrbios aos ideais de bem-estar econômico, paz social e trabalho com dignidade, valores supremos em Estados democráticos modernos. ${ }^{19}$

\title{
40 expansionismo normativo do direito do trabalho
}

Com a autoridade de ter sido um dos dez membros que participaram da elaboração do anteprojeto da CLT, o professor Arnaldo Sussekind (2003, p. 26) entendia pela necessidade de uma reforma trabalhista, mas, ao mesmo tempo, alertava que "[...] no momento que se cogita da atualização da legislação trabalhista brasileira, convém ponderar que, para a necessária harmonização do social com o econômico, é mister a visão sociológica e jurídica dos problemas estruturais e conjunturais, sem menosprezar a força normativa da realidade."

Tendências de marginalização social por meio da desconstrução do direito do trabalho e de reformas que normatizam uma progressiva substituição do legislado pelo contratado, pode ser percebido pela proliferação daquilo que Ricardo Antunes (2009, p. 49) identificava como novas modalidades de trabalho:

\begin{abstract}
Distintas formas de 'empresa enxuta', 'empreendedorismo' 'cooperativismo', 'trabalho voluntário', etc., dentre as mais distintas formas alternativas de trabalho precarizado. $\mathrm{E}$ os capitais utilizaramse de expressões que de certo modo estiveram presentes nas lutas sociais dos anos 1960, como autonomia, participação social, para dar-lhes outras configurações, muito distintas, de modo a incorporar elementos do discurso operário, porém sob clara concepção burguesa. O exemplo das cooperativas talvez seja o mais eloquente, uma vez que, em sua origem, as cooperativas eram reais instrumentos de luta e defesa dos trabalhadores contra precarização do trabalho e o desemprego. $\mathrm{O}$ que vem fazendo os capitais em escala global: criando cooperativas falsas, como forma de precarizar (e destruir) ainda mais os direitos do trabalho. ${ }^{20}$
\end{abstract}

Para que se possa resgatar os ideais do trabalho social, ou seja, o trabalho como instrumento de desenvolvimento da sociabilidade humana, é essencial que se inicie um processo de mutação do arcabouço jurídico brasileiro, destinado a humanizar os princípios estruturantes de uma economia capitalista, incorporando novos valores e ideologias, substituindo as "empresas enxutas" por "empresas humanizadas".

19 Para melhor compreensão da questão, indicamos os estudos produzidos pelo núcleo de pesquisa "Capitalismo Humanista”, da PUC-SP, coordenado pelo professor Ricardo Hasson Sayeg.

20 Atualmente, frente à dominação do capitalismo, as cooperativas são comumente utilizadas como uma forma de descaracterizar verdadeiras relações de trabalho, explorando autênticos trabalhadores que têm seus direitos sociais absolutamente suprimidos. Oculta-se a realidade das relações de emprego subordinado sob a máscara do "cooperativismo" e do "trabalho autônomo". 
Diante desse cenário de alargamento do mercado e do trabalho humano, caracterizado pelo surgimento de novas morfologias laborais, deve-se questionar: como poderá o ordenamento jurídico tutelar todos esses novos sujeitos-trabalhadores, adequando-se à realidade social de forma a alcançar um grau protecionista mais adequado do que o atual?

Inicialmente, deve-se esclarecer que não há solução simplória que se permita reverter, por completo, essa situação contemporânea de marginalização jurídica. Porém, um importante passo aparenta encontrarse no redesenho de novos contornos jurídicos destinados à inclusão social das relações de trabalho lato sensu, assegurando a todos, dentro dos limites das particularidades permitidas por cada função, os direitos constitucionais e legais que regem o direito do trabalho, e correspondem ao próprio fim que justifica o nascimento dessa ciência jurídica.

Os contornos jurídicos para a solução desse desafio de compatibilização do direito laboral com a dinâmica multacional aparentam, sobretudo, repousar sobre duas frentes, de igual importância, quais sejam: a via interpretativa e a via regulamentar. A primeira proposta, de cunho hermenêutico, não será objeto de análise no presente ensaio. Refletiremos, nesse momento, sobre a possibilidade de extensão da proteção do direito do trabalho pela via legislativa, incluindo as relações dos "trabalhadores não empregados", como, a título de exemplo, o caso dos trabalhadores autônomos, avulsos, liberais, eventuais, prestadores de serviços, freelancer, entre tantos outros juridicamente excluídos.

O aumento do espectro protetivo do ordenamento juslaboral deverá ocorrer por intermédio de uma atuação estatal que objetive a equalização dos direitos sociais e fundamentais dos trabalhadores, inspirado pelos ideais de busca por uma igualdade substancial. É com base nessas premissas que a atuação do legislador deverá ser norteada durante essa árdua missão de reestruturação expansionista do sistema trabalhista contemporâneo.

Todavia, é inegável que esse processo de adequação legal não poderá ocorrer de forma universalizante, assegurando todos os direitos sociais e laborais para a totalidade de trabalhadores, independentemente da atividade exercida ou contrato pactuado. Evidente que isso não seria sensato ou, até mesmo, juridicamente possível. Afinal, a título de exemplo, com estender o direito constitucional de proteção à despedida arbitrária a um trabalhador autônomo?

Isso não significa uma refutação da tese expansionista ora defendida. Apenas enaltece a imprescindibilidade da prudência de atuação pelo legislador, tendo em vista que a nova proteção jurídica deverá ser adequada às particularidades inerentes a cada espécie laboral, respeitando as diferenças existentes entre elas. A ampliação da base normativa deverá ocorrer dentro dos limites possíveis, com um aumento racional do feixe de destinatários dos direitos trabalhistas, de forma que os direitos que possam ser universalizados o sejam, e que, aos que não possam, sejam asseguradas apenas as categorias que dele tenham capacidade de usufruir.

Essa definição certamente corresponderá a um inegável esforço do legislador, porém um esforço destinado ao alcance de um objetivo imprescindível para a correção das desigualdades sociais, cada vez mais perceptíveis nas relações trabalhistas. A operacionalização desse novo sistema, destinado à efetivação de maior justiça social e valorização da dignidade humana, deverá:

Em um primeiro momento, identificar qual o estatutário mínimo comum de direitos primordiais ao exercício digno da atividade produtiva de todas as pessoas que trabalham. Ato contínuo, importa verificar quais são as peculiaridades inerentes a cada um dos ramos de atividades prestacionais hoje excluídas da tutela trabalhista e estudar o modo como o ordenamento jurídico pode intervir para regulá-las adequadamente, de modo a favorecer a sua concretização (FRANCESCHET, 2012, p. 324).

Nesse passo, o melhor caminho talvez seja uma reformulação trabalhista que inicie pautada em uma divisão dos direitos fundamentais e sociais dos trabalhadores em dois grupos distintos: os universais, que incidiriam sobre toda e qualquer relação de trabalho, e os específicos, que protegeriam apenas formas individualizadas de trabalho, pois, conforme as peculiaridades e elementos de certas espécies de labor, não teriam a capacidade de produzir efeitos adequados em modalidades distintas. 
Logo, a reestruturação e ampliação da incidência do centro de imputação jurídica protecionista do direito do trabalho não significaria uma garantia de concessão de que todo direito e garantia trabalhista manifestar-se-ia, com a mesma intensidade e forma, em todas as espécies de trabalho, tendo em vista que algumas espécies de trabalho simplesmente não se compatibilizam com determinados direitos ou garantias.

Entre as últimas propostas doutrinárias de universalização dos direitos trabalhistas que se destacam, percebe-se um reconhecimento de que

[...] esse exercício é mais simples para o trabalho eventual, o qual guarda maior similitude com a relação de emprego. Nesse caso, é possível conceber um modelo operacional que conjugue como sujeitos passivos desses direitos fundamentais trabalhistas tanto o Estado, quanto os tomadores de serviços. [...] Já o modelo de proteção mínima aplicável especialmente aos trabalhadores autônomos exige estrutura mais complexa. Algumas demandas desse tipo de trabalhadores diferem daquelas aplicáveis aos empregados, porque decorrentes das peculiaridades do trabalho prestado por conta própria. (FRANCESCHET, 2012, p. 325).

Nesse segundo caso, presencia-se a defesa ${ }^{21}$ da criação de uma espécie de "contribuição sóciotrabalhista" a ser arcada pelos tomadores de serviços "corriqueiros", como forma de financiar quatro direitos fundamentais aos trabalhadores autônomos, quais sejam: FGTS, $13^{\circ}$ salário, férias remuneradas acrescidas de 1/3 e repouso semanal remunerado. Por óbvio que, nesse caso, para que se evite grandes encargos sociais a serem suportados pelo tomador de serviços (pois, quando muito elevados, poderiam acarretar na fraude ou no desincentivo à contratação de trabalhadores autônomos), imprescindível que o Estado desenvolva políticas tributárias que favoreçam esse novo cenário, o que poderá ser feito, entre outras formas, por intermédio da concessão de incentivos fiscais ${ }^{22}$.

As dificuldades e percalços presentes nessa tarefa de reformulação expansionista do direito laboral brasileiro vão desde a identificação até a aplicabilidade de cada direito, tratando ainda de quais as características singulares que cada atividade laboral deverá possuir para que o trabalhador não empregado possa dele usufruir. Essas são questões de grande relevância para o debate de ampliação do núcleo de imputação jurídica do direito do trabalho e qual deve ser o "futuro" a ser buscado por essa ciência desde o presente momento.

Sabe-se que foram significativos os erros cometidos pelo Brasil no que diz respeito às omissões legislativas no momento de transição dos períodos de trabalho escravo para o trabalho livre. Foram 55 anos de demora, após a libertação dos escravos, para uma total ruptura com esse regime e a elaboração de um conjunto normativo que protegesse efetivamente o trabalhador assalariado. Ainda mais grave, foram 100 anos de espera da Lei Áurea (1888) para a equalização dos direitos dos trabalhadores rurais ${ }^{23}$ (1988; foi apenas no ano de 2013 que se estendeu aos domésticos o basilar direito fundamental à limitação da jornada de trabalho (entre outros); e, até a presente data, não possuímos qualquer norma regulamentando a proteção do trabalhador contra a despedida arbitrária, a proteção contra a automação ou definindo o adicional de penosidade.

Esse ritmo de letargia do Congresso Nacional demonstra um caráter postergador do país no que se refere ao reconhecimento das mudanças sociais e econômicas e seu acompanhamento pela necessária alteração legal. Cenário esse que precisa ser modificado.

21 Teoria defendida por Marcella Pagani em "Uma Alternativa para a Expansão do Direito do Trabalho: A Contribuição Sociotrabalhista".

22 A correlação entre encargos sociais e fraudes empresariais sera objeto de análise em capítulo próprio. Todavia, oportuno esclarecer que a concessão de incentivos tributários destinados ao auxílio do processo de efetivação de direitos sociais dos trabalhadores não corresponderia a uma "novidade" em nosso ordenamento. Há importantes medidas fiscais atualmente utilizadas com esse intuito, como exemplo merece destaque o Programa de Alimentação do Trabalhador - PAT (Lei n. 6.321/1976), a licença maternidade de 180 dias (Lei 11.770/2008) e a concessão do vale-cultura (Lei 12.761/2012).

23 Conforme esclarece Marcio Pochamann (2011, p. 129): "a demora de 55 anos para a implantação de um código de trabalho específico ao emprego assalariado no Brasil (1888-1943). A Consolidação das Leis do Trabalho (CLT), que representou muito mais do que a racionalização de um conjunto de mais de cinco mil leis em vigência no início da década de 1940, se deu durante a vigência de regime autoritário (Estado Novo, 1937-1945) e atingiu menos de $15 \%$ dos trabalhadores brasileiros. Destaca-se que a CLT de 1943 voltou-se somente aos empregados assalariados urbanos, enquanto até 1960 o Brasil foi majoritariamente dependente do trabalho agropecuário. O ingresso dos empregados rurais na CLT se deu a partir da década de 1960, com gradual e limitada cobertura dos direitos sociais e trabalhistas [...]. Somente com a Constituição Federal de 1988 os trabalhadores rurais terminaram sendo plenamente incorporados ao sistema de proteção social e trabalhista vigente no Brasil". 
O padrão regulatório trabalhista deve ser reavaliado, para que possa se ajustar, de forma mais dinâmica, à realidade contemporânea. A universalização dos direitos trabalhistas demonstra-se necessária para adequação da tutela juslaboral a essa nova conjuntura econômica e democrática. A marcha expansionista desse ramo jurídico aparenta ser indispensável para uma inclusão efetivas dos trabalhadores que, ainda, encontram-se à margem de consagrados direitos fundamentais.

\section{Considerações finais}

O presente estudo correspondeu a uma análise crítica dos valores da ordem econômica estabelecidos pela Carta de 1988 e os seus desequilíbrios quando analisados por uma perspectiva do mundo do trabalho contemporâneo ${ }^{24}$. Mundo esse que tem experimentado severas influências de uma economia de mercado com tendências neoliberais e que, em um vazio jurídico e político, ameaçam, reiteradamente, quaisquer concepção humanística do ideal de justiça social.

A busca pela efetivação da justiça social no Brasil corresponde a um tema complexo. Afinal, tratase de um país marcado por contrastes, em que o desenvolvimento econômico ocorre pela difusão de métodos impróprios, comumente acompanhados de elevada precarização social. Um país caracterizado por exclusões políticas, econômicas, educacionais, culturais e que continua a analisar a dignidade humana como um luxo a ser usufruído apenas por alguns, portador de um dos piores índices de distribuição de renda e desequilíbrios sociais entre países democráticos, mantendo um cenário de disparidades que pouco evoluiu desde a década de 1970.

Logo, defender teorias norteadas pela busca do reequilíbrio nas distorções enraizadas no modelo atual, aspirando beneficiar os menos favorecidos economicamente e excluídos socialmente, pode aparentar se tratar de uma visão de cunho ideológico, impossível de ser alcançada. Uma verdadeira utopia.

No entanto, a realidade é que a defesa por qualquer das esferas dos direitos fundamentais nunca corresponderá a devaneios frívolos. Não se trata de um luxo, e sim de uma condição essencial à vida contemporânea. É a maior das razões que movem os indivíduos ao convívio em sociedade, é o fim almejado pelo homem e, por isso, ele se sujeita à observância de conjuntos de normas, limites, regras e preceitos que mitigam ou suprimem a sua livre vontade. Incumbe ao Estado assegurar esse fim perseguido, sob pena de nunca alcançar uma convivência verdadeiramente harmônica entre seus cidadãos.

À guisa de conclusão, restou evidenciado que o futuro do direito do trabalho no Brasil carrega desafios imensos, complexos e mutáveis. Há uma alteração na própria morfologia da precariedade. Os debates migrarão do tema "nível de desemprego" para questionamentos acerca da qualidade desse emprego, dominado por postos informais de trabalho (cenário majorado pela "Reforma Trabalhista" de 2017), em que os direitos sociais assegurados ao trabalhador aparentam ser aleatórios, empurrando certas espécies de trabalho para a margem da tutela trabalhista e social.

Faz-se imperativa uma alteração da mentalidade da política e organização do trabalho, que não deverá se limitar, especificamente, ao desemprego, reconhecendo a existência de uma nova enfermidade das sociedades modernas: as múltiplas formas de precarização do trabalho. Não mais bastará o direito ao pleno emprego, e sim a um pleno emprego com dignidade.

Nessa esteira, sob uma perspectiva de Estado Democrático, centralizado em torno da dignidade humana, resta claro que um maior grau de proteção social necessita ser estendido a essa multiplicidade de novas, ou reformadas, morfologias de trabalho. Aceitando a relevância desse processo expansionista em sua plenitude, chegaremos à conclusão de que essa evolução deverá assegurar não apenas alguns

Aspecto que já foi objeto de maior investigação em estudos anteriores, em que apontamos "restar evidente que a sistemática de ordem econômica estabelecida pela Constituição Federal de 1988 não foi alcançada, fazendo-se necessário a busca por novas diretrizes normativas que reconduzam as relações empresariais rumo aos valores constitucionais [...]". (MENDONÇA; ALMEIDA, 2014, p. 203). 
direitos sociais positivados pela CLT. ${ }^{25}$ Deverá, também, abraçar a teoria da horizontalidade dos direitos fundamentais, que impõe o reconhecimento dos direitos do cidadão-trabalhador a essa nova morfologia de trabalho, garantindo os chamados direitos laborais inespecíficos, como "os direitos da personalidade, o direito à informação, o direito à presunção de inocência, o direito à ampla defesa e o direito ao contraditório". (ALMEIDA, 2012, p.296).

\section{Referências}

ALMEIDA, Renato Rua de. Direitos laborais inespecíficos dos trabalhadores. Revista LTr, São Paulo, v. 76, n. 03, p. 295-305, mar. 2012.

ANDRADE, Everaldo Gaspar Lopes de. Curso de Direito do Trabalho. São Paulo: Saraiva, 2008.

ANTUNES, Ricardo. O trabalho, sua nova morfologia e a era da precarização estrutural. Revista Theomai, Buenos Aires, n. 19, p. 47-57, jan./jun. 2009. Disponível em: http://www.revista-theomai.unq. edu.ar/numero19/ArtAntunes.pdf. Acesso em: 10 maio 2015.

AVILA, Humberto. "Neoconstitucionalismo": entre a "Ciência do Direito" e o "Direito da Ciência". Revista Eletrônica de Direito do Estado, Salvador, n. 17, p. 1-19, jan./mar. 2009. Disponível em: https:// revistas.unifacs.br/index.php/redu/article/viewFile/836/595. Acesso em: 10 dez. 2018.

BRAGA, Ruy. Precariado e sindicalismo no Brasil contemporâneo: um olhar a partir da indústria do call center. Revista Crítica de Ciências Sociais, Coimbra, n. 103, p. 25-52, maio 2014.

CALMON, Eliana. As gerações dos direitos e as novas tendências. Revista de Direito do Consumidor, São Paulo, v. 19, n. 39, p. 11-17, jul./set. 2001.

CARELLI, Rodrigo de Lacerda. Formas atípicas de trabalho. São Paulo: LTr, 2004.

COUTINHO, Grijalbo Fernandes. O direito do trabalho flexibilizado por FHC e Lula. São Paulo: LTr, 2009.

DELLAGRAVE NETO, José Affonso. Inovações na legislação trabalhista: reforma trabalhista ponto a ponto. 2. ed. São Paulo: LTr, 2002.

FRANCESCHET, Patrícia Rebouças. O expansionismo do Direito do trabalho no Brasil - possibilidades concretas para a adequada inclusão das diferentes morfologias do trabalho pela via legislativa. Revista LTr, São Paulo, v. 76, n. 03, p. 323, mar. 2012.

FREITAS JUNIOR, Antônio Rodrigues. História universal e direito do trabalho. Revista de Direito do Trabalho, São Paulo, v. 37, n. 144, p. 11-38, out./dez. 2011.

GOMES, Ana Virgínia Moreira. A aplicação do princípio protetor no direito do trabalho. São Paulo: LTr, 2001.

GOMES, Dinaura Godinho Pimentel. A constitucionalização do direito do trabalho: interpretação e aplicação das normas trabalhistas para a efetiva inter-relação dos interesse econômicos com o respeito à dignidade da pessoa humana. Revista de Direito Constitucional e Internacional, São Paulo, v. 15, n. 58, p. 18-38, jan./mar. 2007.

GÓIS, Luiz Marcelo Figueiras de. A caminho de um direito trabalhista constitucional. São Paulo: LTr, 2010.

IMBRIZI, Jaquelina Maria. A formação do indivíduo no capitalismo tardio. São Paulo: HUCITEC, 2005.

Relembramos ao leitor que, conforme alertado no início dessa reflexão acerca do expansionismo tutelar do direito do trabalho, esse aspecto, apesar de dotado de elevada controvérsia e ainda carente de maiores análises científicas no âmbito da academia justrabalhista, não corresponde à problemática central do presente estudo, aparecendo apenas de forma conexa para evidenciar os desafios a serem enfrentados pelo direito laboral contemporâneo. 
MENDONÇA, Maria Lírida Calou de Araújo e; ALMEIDA, Saulo Nunes de Carvalho. Crise do capitalismo e a necessária mutação de paradigmas nas relações justrabalhistas. Pensar - Revista de Ciências Jurídicas, Fortaleza, v. 19, n. 1, p. 201-224, jan./abr. 2014. Disponível em: https://periodicos.unifor.br/ rpen/article/view/2601/pdf. Acesso em: 10 nov. 2018.

MOLL, Luiza Helena. Uma experiência do ensino do novo Direito Econômico. Revista da Faculdade de Direito da Universidade Federal de Minas Gerais, Belo Horizonte, n. 38, p. 395-411, 2000.

NUNES JUNIOR, Vidal Serrano. A cidadania social na constituição de 1998: estratégias de positivação e exigibilidade judicial dos direitos sociais. São Paulo: Verbatim, 2009.

OFFE, Clauss. Capitalismo desorganizado. São Paulo: Brasiliense, 1995.

PAGANI, Marcella. Uma alternativa para a expansão do direito do trabalho: a contribuição sociotrabalhista. 2009. Dissertação (Mestrado em Direito) - Pontifícia Universidade Católica de Minas Gerais, Belo Horizonte, 2009. Disponível em: http://www.biblioteca.pucminas.br/teses/Direito_ PaganiM_1.pdf. Acesso em: 10 mar. 2015.

POCHAMNN, Márcio. Perspectivas das relações de trabalho no Brasil no começo do século 21. In: CACCIAMALI, Maria Cristina; RIBEIRO, Rosana; MACAMBIRA JÚNIOR (org.). Século XXI:

transformações e continuidades nas relações de trabalho. Fortaleza: Banco do Nordeste do Brasil; São Paulo: Universidade de São Paulo, 2011. p. 127-144.

PORTER, Eduardo. $O$ preço de todas as coisas: Por que pagamos o que pagamos. Rio de Janeiro: Objetiva, 2011.

RAMOS, Elival da Silva. Ativismo judicial. São Paulo: Saraiva, 2010.

RODRIGUEZ, Américo Plá. Princípios de direito do trabalho. São Paulo: LTr, 1978.

SAMPAIO, Aluysio. Sobre o Anteprojeto da Consolidação das Leis do Trabalho. Revista de Direito do Trabalho, São Paulo, v. 20, p. 41-50, jul. 1979.

SANDEL, Michael. O que o dinheiro não compra: os limites morais do mercado. Rio de Janeiro:

Civilização Brasileira, 2012.

SARMENTO, Daniel. Direitos fundamentais e relações privadas. 2. ed. Rio de Janeiro: Lummen Juris, 2006.

SOUTO, Marcos Juruena Villela. Ordem econômica na constituição. Revista Tributária e de Finanças Públicas, São Paulo, v. 32, p. 165-172, maio 2000.

SOUTO MAIOR, Jorge Luiz. O direito do trabalho como instrumento de justiça social. São Paulo: LTr, 2000.

STANDING, Guy. O precariado: a nova classe perigosa. Belo Horizonte: Autêntica, 2014.

SUSSEKIND, Arnaldo Lopes. 60 Anos da CLT: uma visão crítica. Revista do TST, São Paulo, v. 69, n. 2, p. 15-26, jul./dez. 2003.

Recebido em: 03/03/2019

Aprovado em: 13/04/2019 